\title{
Overexpression of microRNA-101 causes anti-tumor effects by targeting CREB1 in colon cancer
}

\author{
QINGLIN YANG ${ }^{*}$, WEIJIE YU* ${ }^{*}$ and XIAOLI HAN \\ Department of General Surgery, Yantai Yeda Hospital, Yantai, Shandong 264006, P.R. China
}

Received May 9, 2018; Accepted January 25, 2019

DOI: $10.3892 / \mathrm{mmr} .2019 .9952$

\begin{abstract}
Accumulating evidence has demonstrated that aberrantly expressed microRNAs (miRNAs) are involved in the initiation and progression of numerous types of human cancer. Although a number of miRNAs have been demonstrated to be associated with the diagnosis, progression and prognosis of colon cancer, the function of miRNA-101 (miR-101) in colon cancer remains unclear, and the molecular mechanisms underlying the effects of miR-101 in colon cancer require further investigation. The present study investigated the role of miR-101 in colon cancer, and the results suggested that miR-101 expression levels were significantly decreased in colorectal carcinoma tissues and in three types of colorectal cancer cell lines. Furthermore, overexpression of miR-101 inhibited cell proliferation and migration in HT29 cells. The transcription factor cAMP responsive element binding protein 1 (CREB1) was identified to be a direct target of miR-101 using a luciferase reporter assay, reverse transcription-quantitative polymerase chain reaction analysis and western blot assay. miR-101 overexpression in tumor xenografts in vivo decreased the expression levels of proliferating cell nuclear antigen and CREB1, and suppressed tumor growth. The present results suggested that miR-101 may serve a role in colon cancer by directly targeting CREB1. Collectively, the present study may contribute to the development of improved diagnosis and prognostics for colon cancer.
\end{abstract}

\section{Introduction}

Colorectal cancer is the third most common type of tumor worldwide, and is considered to be the second most common cause of cancer-associated mortality in China $(1,2)$. A number

Correspondence to: Dr Xiaoli Han, Department of General Surgery, Yantai Yeda Hospital, 23-1 Huanghe Road, Yantai, Shandong 264006, P.R. China

E-mail: hanxiaoli0506@163.com

${ }^{*}$ Contributed equally

Key words: microRNA-101, cAMP responsive element binding protein 1 , anti-tumor, colon cancer of risk factors have been identified to be involved in the development of colon cancer, including environmental, lifestyle and genetic factors (3). Previous studies have demonstrated that the incidence of colon cancer has increased due to worsening of lifestyle and environmental factors $(4,5)$. The progression of colon cancer consists of sequential processes in which adenomas may develop into carcinomas, characterized by significant morbidity and mortality (6). Although chemotherapy has been widely used in clinical therapy, drug resistance and rapid tumor growth are the principal obstacles in the treatment of colon cancer. Therefore, novel approaches are required to improve the effectiveness of chemotherapy, inhibiting the initiation and progression of colon cancer. Previous studies demonstrated that microRNAs (miRNAs) can inhibit tumor growth, improving the effectiveness of chemotherapy drugs (7-9).

miRNAs are a class of short noncoding RNAs that serve as important regulators of gene expression (10). The miRBase database contains $>1,500$ human miRNAs that have a role in regulating gene expression at the post-transcriptional level (11), affecting numerous cellular processes during embryonic development and disease (12-14). A number of previous studies demonstrated that miRNAs are associated with diagnosis, progression and prognosis of colon cancer $(15,16)$. miRNA (miR)-143 and miR-145 were identified to be downregulated in precancerous and neoplastic colorectal tissue in 2003 (17). Furthermore, certain miRNAs, including miR-192 and miR-215, have been demonstrated to be associated with carcinogenesis by regulating cell proliferation, invasion, capillary tube formation, cell cycle and angiogenesis $(18,19)$.

Previous studies have demonstrated that miR-101 may be a promising tumor inhibitor and miR-101 expression levels were identified to be decreased in several types of cancer, including embryonal rhabdomyosarcoma, endometrial cancer and hepatocellular carcinoma (20-22). Furthermore, miR-101 may serve as a tumor suppressor by inhibiting the expression level of multiple oncogenes (23-25). However, to the best of our knowledge, the role of miR-101 in the progression of colon cancer is not understood and the potential targets of miR-101 in colon cancer have not yet been identified.

The present study aimed to investigate the expression levels of miR-101 in various colorectal cancer cell lines and colon cancer tissues. Furthermore, the role of miR-101 during colon cancer progression was examined using in vitro and 
in vivo models. Additionally, the direct targets of miR-101 were investigated.

\section{Materials and methods}

Patient information and sample collection. Between February 2016 and May 2018, 20 patients with colon cancer who underwent surgical resection at The Yantai Yeda Hospital (Yantai, China) were selected. Patients with a confirmed cancer diagnosis followed by postoperative pathological examination were enrolled in the study. Patients exhibiting additional types of tumors and patients who underwent preoperative radiotherapy or chemotherapy were excluded from the study. A total of 12 males and 8 females were included in the present study, with an average age of $45.1 \pm 6.9$ years. In total, 4 patients exhibited T1 primary tumor stage, 7 patients presented T2 and nine patients T3. According to the tumor, node and metastasis staging system, 4 patients exhibited colon cancer at stage I, 4 at stage II, 7 at stage III and 5 at stage IV (26). A total of 12 patients exhibited low and middle degrees of differentiation (27) and 8 patients presented high differentiation. Lymph node metastasis was observed in 13 patients. The present study was approved by The Ethics Committee of Yantai Yeda Hospital and informed consent was obtained from all patients. The tumor tissues and adjacent tissues were collected and stored at $-80^{\circ} \mathrm{C}$. Healthy tissues, as confirmed by histopathological assays, at $2 \mathrm{~cm}$ away from the tumor tissue were considered as adjacent normal tissue controls.

Cell culture. Colorectal cancer cell lines (HCT116, SW480 and HT29) and a normal human intestinal epithelial cell line (FHC) were purchased from The Shanghai Institute of Biochemistry and Cell Biology (Chinese Academy of Science, Shanghai, China; http://www.sibcb.ac.cn/). The cells were maintained in Dulbecco's modified Eagle's medium supplemented with $10 \%$ fetal bovine serum (both from Gibco; Thermo Fisher Scientific, Inc., Waltham, MA, USA) in a humidified water-jacketed incubator with $5 \% \mathrm{CO}_{2}$ at $37^{\circ} \mathrm{C}$. The cells were subcultured at $90 \%$ confluence.

Reverse transcription-quantitative polymerase chain reaction analysis (RT-qPCR). Total RNA was isolated from colorectal carcinoma tissues, adjacent normal tissues and cell lines, and the expression levels of miR-101 and CREB1 were examined. The experiments were conducted as previously described (28). Total RNA was extracted using TRIzol reagent (Thermo Fisher Scientific, Inc.) in accordance with the manufacturer's protocol. DNA was synthesized using the TransScript miRNA RT Enzyme Mix (TransGen Biotech Co., Ltd., Beijing, China), according to the manufacturer's protocol, as follows: RT at $50^{\circ} \mathrm{C}$ for $60 \mathrm{~min}$ and inactivation of reverse transcriptase at $70^{\circ} \mathrm{C}$ for $15 \mathrm{~min}$. The primer sequences used were: miR-101 forward, 5'-GCGGCGTACAGTACTGTGATAA-3', reverse, 5'-GTGCAGGGTCCGAGGT-3'; CREB1 forward, 5'-AAC AATGGTACGGATGGGGT-3', reverse, 5'-GCCATAACA ACTCCAGGGGC-3'; GAPDH forward, 5'-AGAAGGCTG GGGCTCArTTG-3', reverse, 5'-AGGGGCCATCCACAG TCTTC-3'. PCR amplification was conducted using SYBR Premix Ex Taq ${ }^{\mathrm{TM}}$ II (Takara Biotechnology Co., Ltd., Dalian, China) with a $20-\mu 1$ reaction system under the conditions of $95^{\circ} \mathrm{C}$ for $30 \mathrm{sec}, 95^{\circ} \mathrm{C}$ for $30 \mathrm{sec}$ and $60^{\circ} \mathrm{C}$ for $30 \mathrm{sec}$ for 40 cycles, following the manufacturer's instructions. RT-qPCR analysis was conducted using the LightCycler ${ }^{\circledR} 480$ Instrument (Roche Applied Science, Penzberg, Germany) GAPDH small nuclear RNA was used as internal reference gene. The $2^{-\Delta \Delta C q}$ method (29) was used to quantify expression.

Cell viability and wound healing assay. HT29 cells transfected with negative control mimics (miR-NC; Thermo Fisher Scientific, Inc.) or miR-101 mimics (Thermo Fisher Scientific, Inc.) were seeded into 96-well plates, using Lipofectamine ${ }^{\circledR}$ 2000 reagent (Invitrogen; Thermo Fisher Scientific, Inc.). The following sequences were used: miR-101 mimics 5'-UAC AGUACUGUGAUAACUGAA-3'. The negative control for the agomir was sense 5'-UUCUCCGAACGUGUCACG UTT-3'. The final concentration of miRNA mimics was $50 \mathrm{nM}$. Following a 48-h incubation, viability was evaluated using a Cell Counting Kit-8 (CCK-8; Dojindo Molecular Technologies, Inc., Kumamoto, Japan) according to the manufacturer's protocol. Cell proliferation was analyzed by measuring the absorbance at $450 \mathrm{~nm}$ using a microplate reader. HT29 cells were seeded at a density of $5 \times 10^{5}$ into 6 -well plates and cultured under standard conditions. When the confluence reached $100 \%$, a scratch was made using a $200 \mu 1$ pipette tip. Cell migration was determined by counting the cells migrating into the scraped area. The process of wound closure was monitored and images were captured at 0 and $12 \mathrm{~h}$ under an inverted microscope at $\mathrm{x} 400$ magnification and counted.

Bioinformatics analysis. The targets and binding sites of miR-101 were predicted using a number of online tools and databases, including EIMMO (version2; http://www.mirz. unibas.ch/EIMMo2/) (30), miRBase (version21; http://www. mirbase.org/) (31) and TargetScan (version 7.2; http://www. targetscan.org/) (32). CREB1 was predicted to be a target of miR-101 in silico and was validated in vitro using a dual luciferase assay.

Dual luciferase assays. HT29 cells were plated in a 24-well plate and cotransfected with $200 \mathrm{ng}$ pMIR-CREB1-wild-type (WT) or pMIR-CREB1-mutant (Mut)plasmid (Promega Corporation, Madison, WI, USA), together with miR-101 or NC mimics using Lipofectamine ${ }^{\circledR} 2000$ reagent (Invitrogen; Thermo Fisher Scientific, Inc.) together with miR-101 mimics or miR-NC at a concentration of $100 \mathrm{nM}$. A total of $10 \mathrm{ng}$ of the pRL-TK vector containing the Renilla luciferase gene (Promega Corporation) was transfected using Lipofectamine ${ }^{\circledR}$ 2000 (Invitrogen; Thermo Fisher Scientific, Inc.). Reporter activity was determined at $48 \mathrm{~h}$ after transfection. The luciferase activity was analyzed using a Dual-Luciferase Reporter Assay system (Promega Corporation) according to the manufacturer's protocols.

Western blot analysis. Cellular proteins were extracted by RIPA buffer (ab156034; Abcam, Cambridge, UK). Total protein concentration was quantified using BCA Protein Assay kit (Pierce; Thermo Fisher Scientific, Inc). The proteins (50 $\mu \mathrm{g} /$ well) were transferred onto a polyvinylidene difluoride membrane following electrophoresis with $12 \%$ SDS-PAGE. 
The membrane was incubated for $1 \mathrm{~h}$ at $37^{\circ} \mathrm{C}$ in $5 \%$ non-fat dry milk powder. A rabbit polyclonal antibody against CREB1 (ab31387, 1:1,000, Abcam), and a mouse monoclonal antibody for GAPDH (ab8245, 1:5,000, Abcam) were used as the primary antibodies. The membranes were subsequently probed with a goat anti-rabbit horseradish peroxidase-conjugated secondary antibody (ab150077, 1:20,000, Abcam) at room temperature for $2 \mathrm{~h}$. Signals were detected following incubation with a SuperSignal West Pico chemiluminescent substrate (Pierce; Thermo Fisher Scientific, Inc.), and imaged using a ChemiDoc XRS system (Bio-Rad Laboratories, Inc., Hercules, CA, USA), and quantified using Quantity One software (version 4.6.8; Bio-Rad Laboratories, Inc.).

Mouse xenograft model. HT29 cells were transfected with $150 \mathrm{nMmiR}-101$ mimics or miR-NCusing Amaxa-Nucleofector II (Amaxa Biosystems, Inc, Gaithers- burg, MD). Following transfection, cells were incubated in fresh medium for $24 \mathrm{~h}$ at $37^{\circ} \mathrm{C}$. Subsequently, the cells were collected and washed with ice-cold PBS three times and subsequently suspended in PBS at a concentration of $5 \times 10^{6}$ cells $/ \mathrm{ml}$. Nude mice $(\mathrm{n}=12$, male; age, 06-08 weeks; weight, 18-22 g) were purchased from the Shanghai Laboratory Animal Center Laboratory Animal Co., Ltd. (Shanghai, China). These mice were housed five per cage under the following conditions: Constant temperature, $25^{\circ} \mathrm{C}$; humidity, 40-75\%; $12 \mathrm{~h}$ light/dark cycle and free access to food and water. These mice were divided into two groups; one group $(n=6)$ was inoculated with cells transfected with miR-101 mimics, and the other group $(n=6)$ with cells transfected with miR-NC. Mice were xenografted with transfected tumor cells by subcutaneous injection of $5 \times 10^{5}$ cells in $100 \mu \mathrm{l}$. Tumor growth was measured every 3 days from the 7 th day. Tumor volume (V) was monitored by measuring the length (L) and width (W) with calipers and calculated with the following formula: $\mathrm{V}=\left(\mathrm{L} \mathrm{x} \mathrm{W}^{2}\right) \times 0.5$. The tumors were isolated from the mice with a surgical scissor, weighed on the $22 \mathrm{nd}$ day, and subsequently preserved in $4 \%$ paraformaldehyde at $4^{\circ} \mathrm{C}$ for subsequent immunohistochemical analysis. All experiments involving animals were approved by The Ethics Committee of Yantai Yeda Hospital.

Immunohistochemical analysis. Tumor tissues were fixed overnight in $4 \%$ paraformaldehyde at room temperature, dehydrated, permeabilized and embedded in paraffin using a Leica embedding machine (Leica Microsystems, Inc., Buffalo Grove, IL, USA). Using an RM2016 slicing machine (Leica, Wetzlar, Germany), the paraffin blocks were sliced into $5-\mu \mathrm{m}$ serial paraffin sections, which were placed in an oven overnight. Hydrated tissue sections were treated with $3 \%$ hydrogen peroxide solution to block endogenous peroxidase; the sections were subsequently acid-fixed using a pre-configured citrate buffer and the sections were placed in liquid using a microwave heating method. Following repair, blocking was performed with 5\% normal goat serum albumin (Thermo Fisher Scientific, Inc.) at room temperature for $20 \mathrm{~min}$. Sections were incubated overnight at $4^{\circ} \mathrm{C}$ with primary antibodies (rabbit polyclonal antibodies against CREB1, ab31387, 1:100; Abcam) and proliferating cell nuclear antigen (PCNA, ab18197, 1:50, Abcam). Then incubated with the secondary goat anti-rabbit IgG (horseradish peroxidase) antibody (ab150077, 1:200;
Abcam) at $37^{\circ} \mathrm{C}$ for $30 \mathrm{~min}$. Following 3,3'-diaminobenzidine staining at room temperature for $10 \mathrm{~min}$, hematoxylin staining was performed at room temperature for $2 \mathrm{~min}$, followed by dehydration and neutral resin mounting. Images were observed with a routine microscope at x400 magnification and counted. The intensity of immunohistochemical staining was analyzed and quantified in three randomly selected fields per section using Image-Pro Plus software (version 6.0; Media Cybernetics, Inc., Rockville, MD, USA).

Statistical analysis. All quantitative data for statistical analyses were from at least three independent experiments. Data are presented as the mean \pm standard deviation. Comparisons between two groups were performed using Student's t-test, and paired Student's t-test was used to analyze paired data. Comparisons among three or more groups were performed using analysis of variance followed by Bonferroni post hoc test. $\mathrm{P}<0.05$ was considered to indicate a statistically significant difference.

\section{Results}

miR-101 is significantly downregulated in cancer cell lines and colon cancer tissues. The expression of miR-101 was determined in colon cancer tissues from 20 patients. The expression level of miR-101 in colorectal carcinoma tissues and the adjacent normal tissues was measured using RT-qPCR. Significant downregulation of the expression level of miR-101 was identified in all 20 colorectal carcinoma tissues compared with adjacent normal tissue (Fig. 1A). Furthermore, the expression level of miR-101 was significantly upregulated in the normal human intestinal epithelial cell line (FHC) compared with colorectal cancer cell lines (SW480, HT29 and HCT116; Fig. 1B). Collectively, the RT-qPCR results suggested that miR-101 may be involved in the development and progression of colon cancer.

miR-101 inhibits tumor cell proliferation and migration. Due to the downregulation of the expression level of miR-101 in colorectal cancer tissues and cell lines, it was hypothesized that miR-101 may inhibit tumor cell proliferation and migration. In order to investigate the role of miR-101 on the proliferation of HT29 cells, HT29 cells were transfected with miR-101 mimics or miR-NC. RT-qPCR was performed to examine the expression level of miR-101, and a significant upregulation of miR-101 was detected following miR-101 overexpression (Fig. 2A). CCK-8 cell viability assay suggested that overexpression of miR-101 significantly inhibited the proliferation of HT29 cells (Fig. 2B). Using a wound healing assay, it was identified that overexpression of miR-101 significantly repressed the migration of HT29 cells (Fig. 2C). Collectively, the present results suggested that overexpression of miR-101 levels may inhibit the malignant features of colorectal cancer, including cell proliferation and migration.

miR-101 regulates CREBI expression by targeting the 3'-untranslated region (UTR) of CREB1. Potential targets of miR-101 were predicted using miRBase (http://www.mirbase. org/), and miR-101 binding sites were identified in the 3'-UTR of CREB1, one of the putative targets (Fig. 3A). To investigate whether miR-101 interacts with the CREB1 transcript 
in vitro, the miR-101 binding sites in the 3'-UTR of CREB1 were mutated, and a dual luciferase assay was conducted (Fig. 3A). The pMIR-CREB1-WT plasmid, containing the 3'-UTR of CREB1, or the pMIR-CREB1-Mut reporter, containing a mutated form of the 3'-UTR, was cotransfected into HT29 cells together with miR-101 mimics or miR-NC mimics and luciferase assays were performed. Transfection of miR-101 mimics significantly decreased the luciferase activity of pMIR-CREB1-WT reporter plasmid compared with the miR-NC mimics. However, miR-101 overexpression did not affect the luciferase activity of the pMIR-CREB1-Mut reporter plasmid compared with the miR-NC mimics (Fig. 3B). Collectively, the present results suggested that miR-101 may be able to bind directly to the 3'-UTR of CREB1 to regulate gene expression. To investigate whether miR-101 regulated the expression of CREB1, HT29 were transfected with miR-101 and the protein and mRNA expression levels of CREB1 were examined using western blot and RT-qPCR analysis, respectively. miR-101 overexpression significantly decreased the mRNA and protein expression levels of CREB1 (Fig. 4). The present results suggested that miR-101 was able to decrease the expression level of CREB1 in colon cancer cells by directly binding the 3'-UTR of CREB1.

Expression of CREB1 in cell lines and colon cancer tissues. To investigate the role of CREB1 in colon cancer progression, the expression level of CREB1 was assessed using RT-qPCR in three human colorectal cancer cell lines (SW480, HT29 and HTC116) and the FHC cell line. Furthermore, the expression level of CREB1 was investigated in colorectal carcinoma tissues and adjacent normal tissues. The expression level of CREB1 was significantly increased in the three tumor cell lines compared with the FHC cell line (Fig. 5A). Furthermore, the expression levels of CREB1 were significantly upregulated in the tumor tissues compared with the adjacent normal tissues (Fig. 5B). Notably, the immunochemistry results suggested that the protein expression of CREB1 was significantly upregulated in the tumor tissues compared with the normal tissues (Fig. 5C). Additionally, it was identified, by western blotting, that the protein expression level of CREB1 in colon cancer tumor tissues was significantly increased compared with adjacent normal tissues (Fig. 5D). Collectively, the present results suggested that miR-101 may serve an important role in colon cancer by inhibiting CREB1 expression.

miR-101 inhibits tumor growth in mouse. HT29 cells were injected into mice to generate a murine xenograft model of colon carcinoma. Transfected cells were injected subcutaneously into the back of nude mice. The tumor growth rate was measured every 3 days and at the end of the experiment the tumors were surgically removed, weighed and imaged (Fig. 6). The present results suggested that overexpression of miR-101 suppressed tumor growth in vivo. Subsequently, immunohistochemical analysis was performed using anti-PCNA and anti-CREB1 antibodies to detect proliferating cells and CREB1 protein expression levels, respectively. The number of cells positive for PCNA and CREB1 staining was significantly decreased in xenograft tumor tissues produced from HT29 cells transfected with miR-101 compared with miR-NC xenografts (Fig. 7A). Additionally, the protein expression level of
$\mathbf{A}$

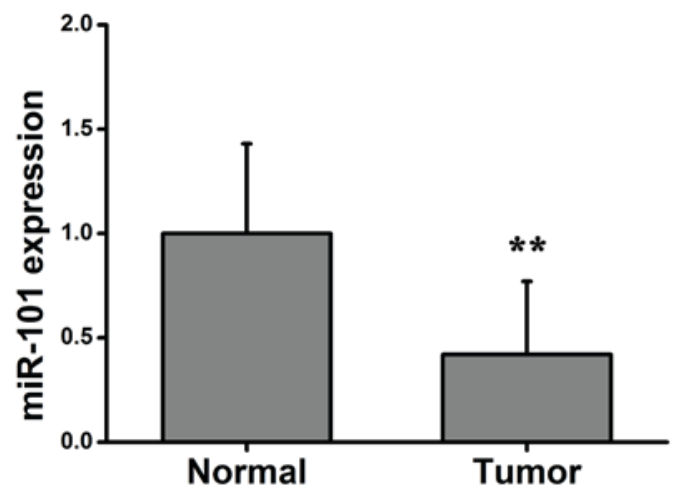

B

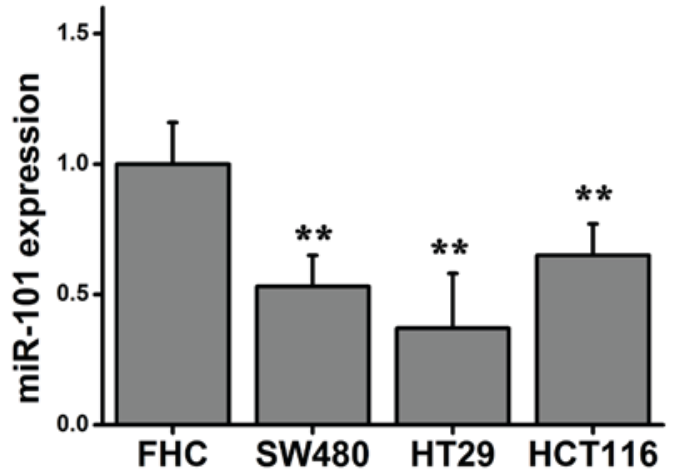

Figure 1. miR-101 is differentially expressed in colon cancer tissues and cell lines. (A) miR-101 expression in colorectal carcinoma tissues and adjacent normal tissues. Paired Student's t-test, ${ }^{* *} \mathrm{P}<0.01$ vs. normal. (B) miR-101 expression in the normal human intestinal epithelial cell line (FHC) and three colorectal cancer cell lines (SW480, HT29 and HTC116). One-way analysis of variance followed by Bonferroni post hoc test, ${ }^{* *} \mathrm{P}<0.01$ vs. FHC. miR-101, microRNA-101.

CREB1 was significantly increased compared with adjacent normal tissue in nude mice xenografted with colon cancer cells, as detected by western blotting (Fig. 7B), suggesting that CREB1 may be involved the development and progression of colon cancer. The present results suggested that overexpression of miR-101 led to downregulation of the expression level of CREB1 and significant inhibition of tumor growth.

\section{Discussion}

miRNAs are important gene regulators and are involved in numerous cellular processes, including proliferation, migration, apoptosis, differentiation and carcinogenesis (33-36). Furthermore, miRNAs have been identified to be associated with the initiation and progression of malignant tumors (37). Although previous studies investigated the role of miR-101 in colon cancer (38), the present results suggested a number of novel findings. Overexpression of miR-101 served anti-proliferative and anti-migratory roles in HT29 cells. In addition, in vivo results suggested that miR-101 downregulated CREB1 in a tumor xenograft murine model. Furthermore, CREB1 was identified as a potential target of miR-101 and downregulation of CREB1 may be one of the underlying 
A

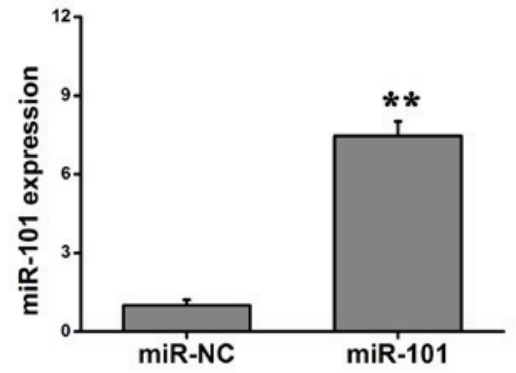

B

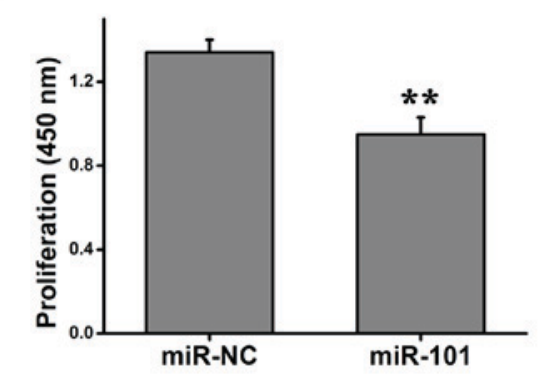

C

miR-NC

miR-101
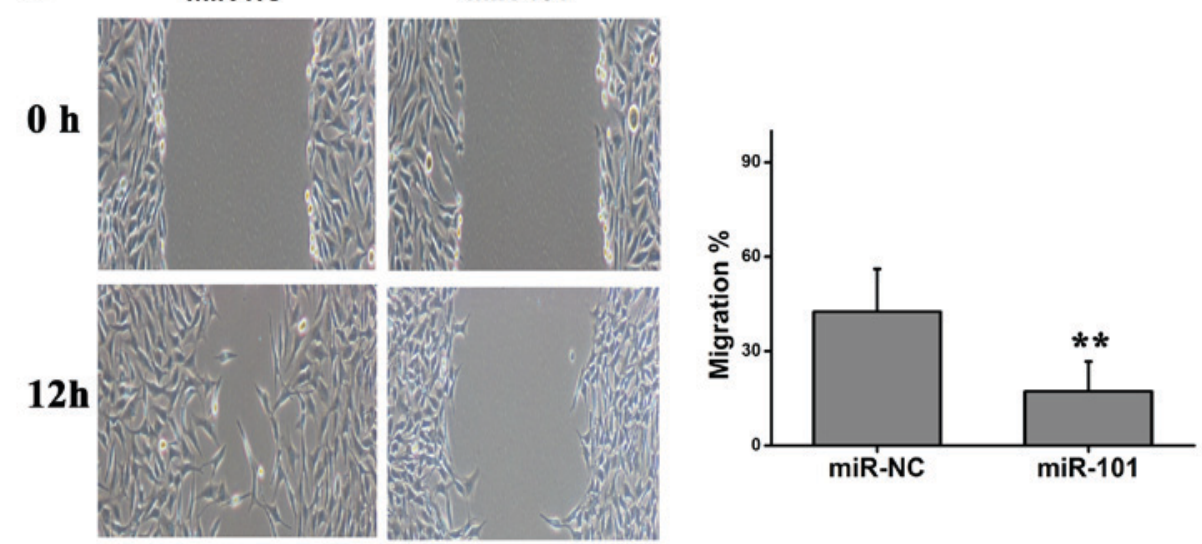

Figure 2. Effects of miR-101 in HT29 cells. (A) Quantification of the expression level of miR-101 using reverse transcription-quantitative polymerase chain reaction analysis. (B) Cell viability following miR-101 overexpression. (C) Representative images of wound healing assays of cells transfected with miR-101 or miR-NC. Student's t-test was used. ${ }^{* *} \mathrm{P}<0.01$. miR, microRNA; NC, negative control.

A

Position 6286-6292 of CREB1 3' UTR

hsa-miR-101-3p.1

Mut-CREB1 3'UTR
5' ...UAAAGUGCUUUUUCUUACUGUAA...

| | | ||

3' aAgUCAAUAgUguCAUGACAU

5'...UAAAgUgCUUUUUCUUUGACAUA...

B

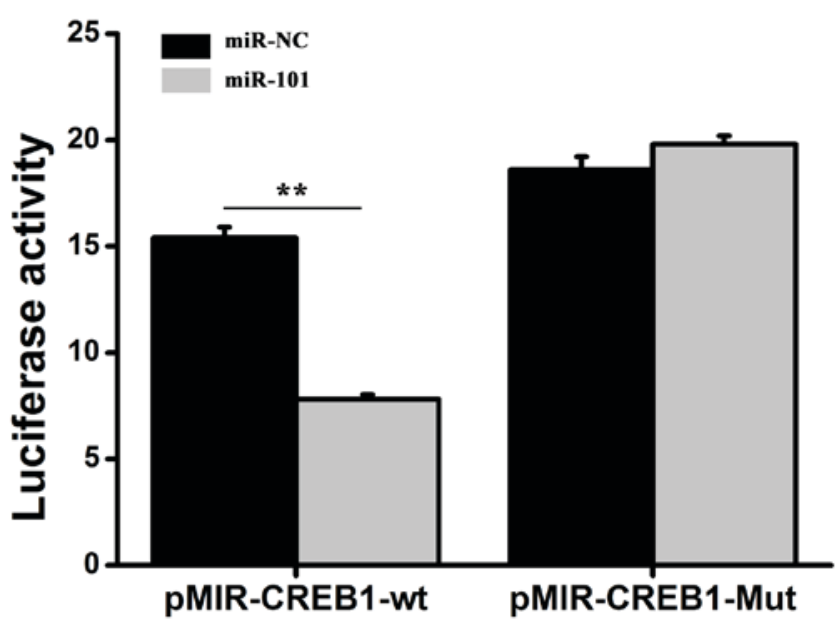

Figure 3. miR-101 regulates CREB1 expression in vitro by binding to the 3'-UTR of CREB1. (A) Predicted target sequence of miR-101 in the CREB1 3'-UTR. (B) Luciferase activity of cells cotransfected with reporter plasmids containing the WT or Mut CREB1 3'-UTR together with miR-101 mimics and negative control miR mimics (miR-NC). Two-way analysis of variance followed by Bonferroni post hoc test. ${ }^{* *} \mathrm{P}<0.01$. CREB1, cAMP responsive element binding protein 1; UTR, untranslated region; miR, microRNA; Mut, mutant; NC, negative control; WT, wild-type. 
$\mathbf{A}$
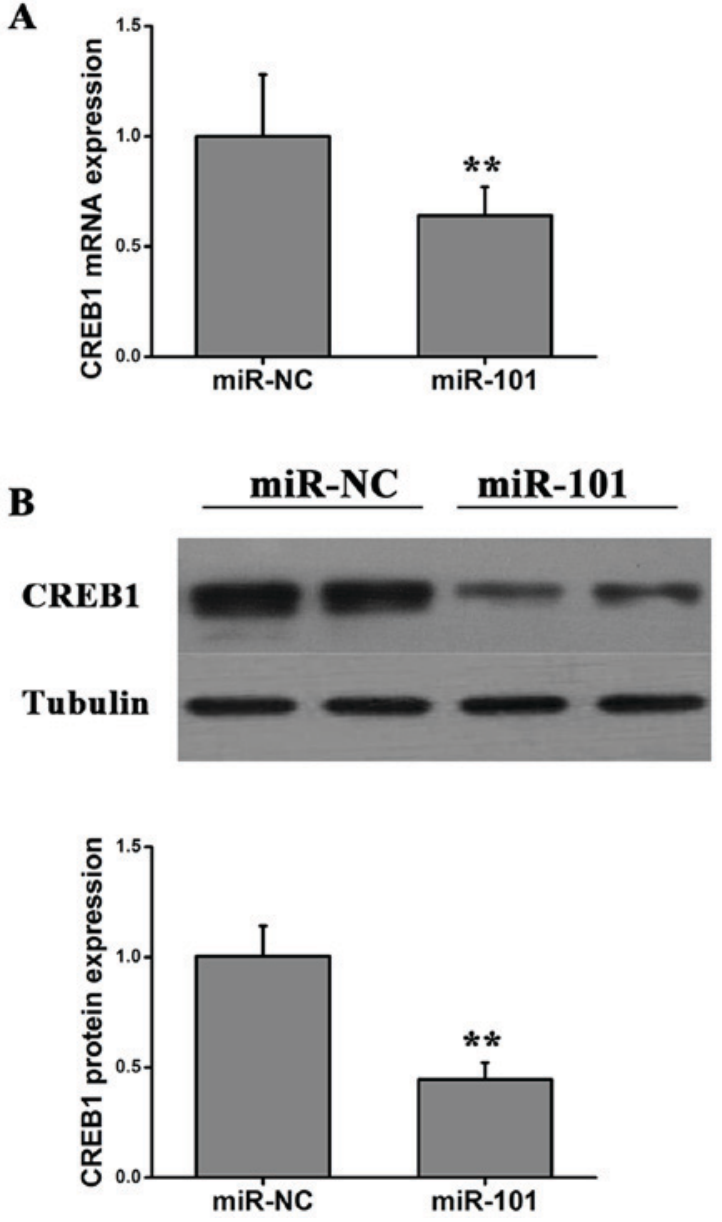

Figure 4. Expression of CREB1 in cells transfected with miR-101 or miR-NC. (A) Quantification of the expression level of CREB1 using reverse transcription-quantitative polymerase chain reaction analysis. (B) CREB1 protein expression level was determined by western blotting. Student's t-test, ${ }^{* *} \mathrm{P}<0.01$ vs. miR-NC. CREB1, cAMP responsive element binding protein 1; miR, microRNA; NC, negative control.

mechanisms that mediate the effect of miR-101 in colon cancer suppression. Therefore, the tumor suppressive effects of miR-101 in colon cancer may involve the direct targeting of CREB1.

Multiple miRNAs have been observed to be dysregulated in different types of human colorectal cancer (39-43). Among them, miR-143 and miR-145 were the first miRNAs observed to be downregulated in colorectal neoplasms (17). Schepeler et al (44) demonstrated that the proliferation of three colorectal cancer cell lines (LS174T, DLD1 and HCT116) was significantly inhibited following transfection with miR-145, suggesting that miR-145 may have tumor suppressive roles. Additionally, miR-143 may serve an important role in colorectal cancer cell proliferation by targeting the KRAS proto-oncogene GTPase, which is involved in various signaling pathways that regulate multiple cellular biological processes $(45,46)$. By contrast, a group of oncogenic miRNAs, including miR-17, miR-18a and miR-19a, may be involved in the development of adenoma into carcinoma $(47,48)$.

Numerous studies have observed that miR-101 (sequence TACAGTACTGTGATAACTGAA) may function as a tumor inhibitor (49). Vella et al (20) demonstrated that miR-101 may repress the migration of embryonal rhabdomyosarcoma cells by suppressing enhancer of zeste homolog 2 . Furthermore, overexpression of miR-101 inhibited the proliferation and migration of endometrial cancer cells and induced cell apoptosis. However, the mechanism underlying the association between miR-101 and colon cancer progression remains unclear. In the present study, it was hypothesized that downregulation of miR-101 may lead to colon cancer progression, and the occurrence of a malignant phenotype. The present study observed that miR-101 was significantly downregulated in the human cancer tissues compared with the adjacent normal colon tissues. In addition, the expression level of miR-101 was significantly downregulated in three colorectal cancer cell lines, SW480, HT29 and HCT116, compared with a normal human intestinal epithelial cell line (FHC). The present results suggested that miR-101 may contribute to the initiation and progression of colon cancer.

Therefore, downregulation of miR-101 may represent a feature of metastatic colon cancer cells. miR-101 expression was significantly downregulated in invasive tumor cells, and the expression of miR-101 has been identified to be downregulated in undifferentiated colon cancer cells, which exhibit an aggressive phenotype. The in vitro experiments in the present study supported the hypothesis that overexpression of miR-101 may regulate the malignant features of colon cancer cells. HT29 cells overexpressing miR-101 exhibited a significant decrease in cell proliferation and migration. The present finding supports the observations in a previous study by Strillacci et al (50).

Accumulating evidence demonstrated that numerous biological events, including inflammation (51), epithelial-mesenchymal transition (52) and hypoxia response (53), are involved in the establishment of a malignant phenotype in colon cancer cells. The present study investigated the underlying mechanisms of miR-101 in the development and progression of colon cancer. Notably, miR-101 significantly inhibited the expression level of CREB1 by directly binding to the 3'-UTR of CREB1. The association between miR-101 and CREB1 was supported by experiments performed in colon cancer cells transfected with miR-101. Overexpression and activation of miR-101 led to a significant decrease of the mRNA and protein expression levels of CREB1. Furthermore, CREB1 expression levels were significantly increased in various colon cancer cell lines and colon cancer tissues, and the immunohistochemical results confirmed that the protein expression level of CREB1 in tumor tissues was significantly upregulated compared with adjacent normal tissues. Furthermore, in vivo experiments suggested that CREB1 may be a key target of miR-101, as overexpression of miR-101 inhibited tumor growth and downregulated the expression level of CREB1. The miR-101/CREB1 pathway may represent a potential novel mechanism of colon cancer progression and it may facilitate the prevention and the treatment of colon cancer.

Collectively, the present study suggested that miR-101 may serve a role as a tumor inhibitor. Overexpression of miR-101 suppressed cell proliferation and migration in vitro and inhibited tumor growth in xenograft mouse models in vivo, with CREB1 being a potential functional target of miR-101. The present results suggested an association between the miR-101/ CREB1 pathway and tumor progression, and miR-101 may be an important factor involved in this signaling pathway. 
$\mathbf{A}$

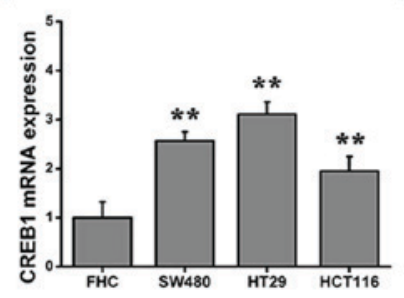

B

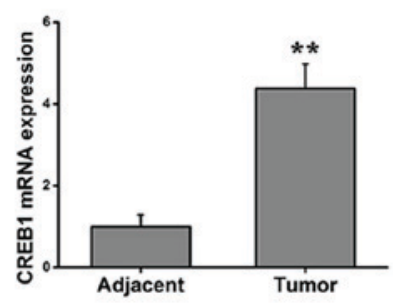

Tumor
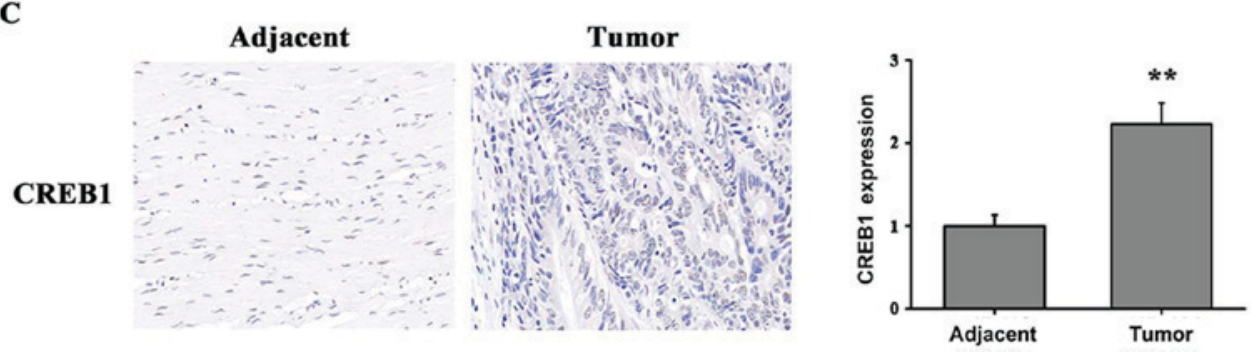

D

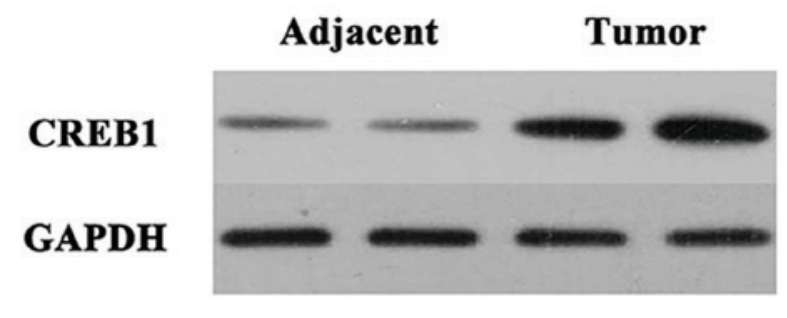

Figure 5. Expression of CREB1 in colon cancer tissues and cell lines. (A) CREB1 expression levels in a normal human intestinal epithelial cell line (FHC) and colorectal cancer cell lines (SW480, HT29 and HTC116). One-way analysis of variance followed by Bonferroni post hoc test, ${ }^{* *} \mathrm{P}<0.01$ vs. FHC. (B) CREB1 protein expression level in colorectal carcinoma tissues $(n=20)$ and adjacent normal tissues $(n=20)$. (C) CREB1 protein expression level examined by immunohistochemical staining. Student's t-test, ${ }^{* *} \mathrm{P}<0.01$ vs. adjacent. (D) Protein expression level of CREB1 in adjacent tissue and tumor tissue measured by western blotting. Student's t-test, ${ }^{* * *} \mathrm{P}<0.01$ vs. adjacent. CREB1, cAMP responsive element binding protein 1 .

$\mathbf{A}$

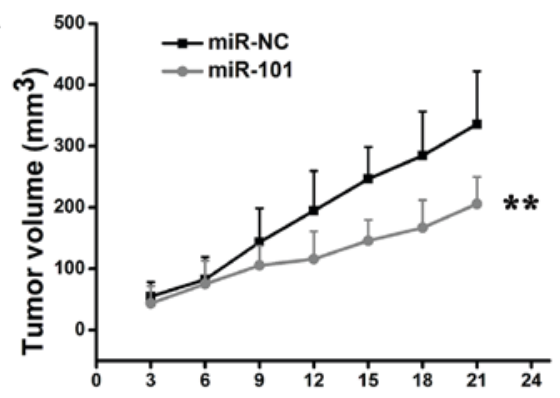

B

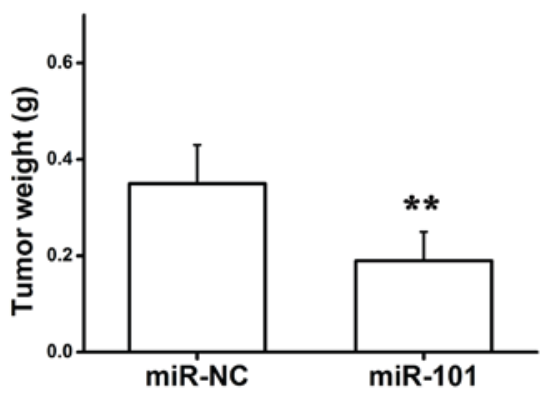

Figure 6. miR-101 inhibits tumor growth in vivo. (A) Tumor volume growth curves. Two-way analysis of variance followed by Bonferroni post hoc test. (B) Tumor weight. Student's t-test, ${ }^{* *} \mathrm{P}<0.01$ vs. miR-NC. miR, microRNA; $\mathrm{NC}$, negative control.
$\mathbf{A}$

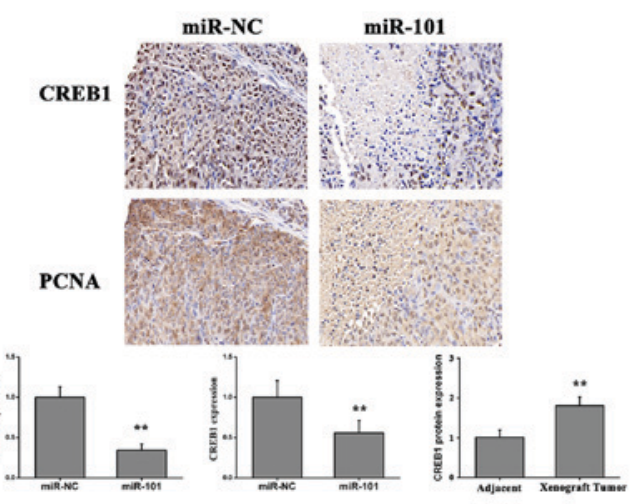

B

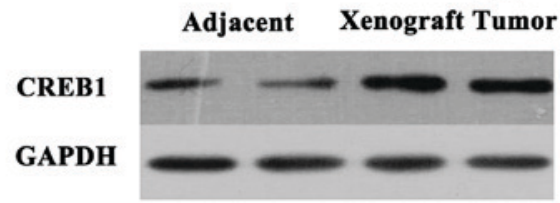

Figure 7. miR-101 downregulates the expression of CREB1 in vivo. (A) Effects of miR-101 on CREB1 and PCNA protein expression levels as measured by immunohistochemical staining $(\mathrm{n}=10)$, and quantification of the expression level of PCNA in xenografts from cells transfected with miR-101 tumors, using reverse transcription-quantitative polymerase chain reaction analysis. ${ }^{* *} \mathrm{P}<0.01$ vs. miR-NC or adjacent. (B) Protein expression level of CREB1 in adjacent tissues and xenograft tumor tissues. CREB1, cAMP responsive element binding protein 1; miR-101, microRNA-101; PCNA, proliferating cell nuclear antigen; $\mathrm{NC}$, negative control. 
Collectively, this study suggested that miR-101 could be a therapeutic target in colon cancer, and that investigating the miR-101/CREB1 pathway may facilitate the development of a novel therapeutic strategy to treat colon cancer.

\section{Acknowledgements}

Not applicable.

\section{Funding}

No funding was received.

\section{Availability of data and materials}

The datasets used and/or analyzed during the current study are available from the corresponding author on reasonable request.

\section{Authors' contributions}

QY and WY designed the study, performed experiments, analyzed the data and wrote the manuscript. WY and $\mathrm{XH}$ performed the experiments. QY and XH analyzed the data and drafted the manuscript.

\section{Ethics approval and consent to participate}

The present study was approved by The Ethics Committee of Yantai Yeda Hospital and informed consent was obtained from all patients.

\section{Patient consent for publication}

Not applicable.

\section{Competing interests}

The authors have no competing interests.

\section{References}

1. Gellad ZF and Provenzale D: Colorectal cancer: National and international perspective on the burden of disease and public health impact. Gastroenterology 138: 2177-2190, 2010.

2. Siegel R, Naishadham D and Jemal A: Cancer statistics, 2013. CA Cancer J Clin 63: 11-30, 2013.

3. Jeon J, Du M, Schoen RE, Hoffmeister M, Newcomb PA, Berndt SI, Caan B, Campbell PT, Chan AT, Chang-Claude J, et al: Determining risk of colorectal cancer and starting age of screening based on lifestyle, environmental, and genetic factors Gastroenterology 154: 2152-2164.e19, 2018.

4. Torre LA, Bray F, Siegel RL, Ferlay J, Lortet-Tieulent J and Jemal A: Global cancer statistics, 2012. CA Cancer J Clin 65: 87-108, 2015.

5. Sjo OH, Berg M, Merok MA, Kolberg M, Svindland A, Lothe RA and Nesbakken A: Peritoneal carcinomatosis of colon cancer origin: Highest incidence in women and in patients with right-sided tumors. J Surg Oncol 104: 792-797, 2011.

6. Vermeer NC, Snijders HS, Holman FA, Liefers GJ, Bastiaannet E, van de Velde CJ and Peeters KC: Colorectal cancer screening: Systematic review of screen-related morbidity and mortality. Cancer Treat Rev 54: 87-98, 2017.

7. Mori F, Ferraiuolo M, Santoro R, Sacconi A, Goeman F, Pallocca M, Pulito C, Korita E, Fanciulli M, Muti P, et al: Multitargeting activity of miR-24 inhibits long-term melatonin anticancer effects. Oncotarget 7: 20532-20548, 2016.
8. Yogin P, Nirav S, Lee JS, Markoutsa E, Jie C, Liu S, Botbyl R, Reisman D, Xu P and Chen H: A novel double-negative feedback loop between miR-489 and the HER2-SHP2-MAPK signaling axis regulates breast cancer cell proliferation and tumor growth. Oncotarget 7: 18295-18308, 2016.

9. Konishi H, Fujiya M, Ueno N, Moriichi K, Sasajima J, Ikuta K, Tanabe H, Tanaka $\mathrm{H}$ and Kohgo Y: microRNA-26a and -584 inhibit the colorectal cancer progression through inhibition of the binding of hnRNP A1-CDK6 mRNA. Biochem Biophys Res Commun 467: 847-852, 2015.

10. Tili E, Michaille JJ and Calin GA: Expression and function of micro-RNAs in immune cells during normal or disease state. Int J Med Sci 5: 73-79, 2008.

11. He L and Hannon GJ: MicroRNAs: Small RNAs with a big role in gene regulation. Nat Rev Genet 5: 522-531, 2004.

12. Kantharidis P, Wang B, Carew RM and Lan HY: Diabetes complications: The microRNA perspective. Diabetes 60: 1832-1837, 2011

13. Trionfini P and Benigni A: MicroRNAs as master regulators of glomerular function in health and disease. J Am Soc Nephrol 28: 1686-1696, 2017.

14. Kato M and Natarajan R: MicroRNAs in diabetic nephropathy: Functions, biomarkers, and therapeutic targets. Ann N Y Acad Sci 1353: 72-88, 2015

15. Srivastava K and Srivastava A: Comprehensive review of genetic association studies and meta-analyses on miRNA polymorphisms and cancer risk. PLoS One 7: e50966, 2012.

16. Tokarz $\mathrm{P}$ and Blasiak $\mathrm{J}$ : The role of microRNA in metastatic colorectal cancer and its significance in cancer prognosis and treatment. Acta Biochim Pol 59: 467-474, 2012.

17. Michael MZ, O' Connor SM, van Holst Pellekaan NG, Young GP and James RJ: Reduced accumulation of specific microRNAs in colorectal neoplasia. Mol Cancer Res 1: 882-891, 2003.

18. Song B, Wang Y, Kudo K, Gavin EJ, Xi Y and Ju J: miR-192 Regulates dihydrofolate reductase and cellular proliferation through the p53-microRNA circuit. Clin Cancer Res 14: 8080-8086, 2008.

19. Braun CJ, Zhang X, Savelyeva I, Wolff S, Moll UM, Schepeler T, Ørntoft TF, Andersen CL and Dobbelstein M: p53-Responsive micrornas 192 and 215 are capable of inducing cell cycle arrest. Cancer Res 68: 10094-10104, 2008.

20. Vella S, Pomella S, Leoncini PP, Colletti M, Conti B, Marquez VE, Strillacci A, Roma J, Gallego S, Milano GM, et al: MicroRNA-101 is repressed by EZH2 and its restoration inhibits tumorigenic features in embryonal rhabdomyosarcoma. Clin Epigenetics 7: 82, 2015.

21. Konno Y, Dong P, Xiong Y, Suzuki F, Lu J, Cai M, Watari H, Mitamura T, Hosaka M, Hanley SJ, et al: MicroRNA-101 targets EZH2, MCL-1 and FOS to suppress proliferation, invasion and stem cell-like phenotype of aggressive endometrial cancer cells. Oncotarget 5: 6049-6062, 2014.

22. Xu L, Beckebaum S, Iacob S, Wu G, Kaiser GM, Radtke A, Liu C, Kabar I, Schmidt HH, Zhang X, et al: MicroRNA-101 inhibits human hepatocellular carcinoma progression through EZH2 downregulation and increased cytostatic drug sensitivity. J Hepatol 60: 590-598, 2014.

23. Su H, Yang JR, Xu T, Huang J, Xu L, Yuan Y and Zhuang SM: MicroRNA-101, down-regulated in hepatocellular carcinoma, promotes apoptosis and suppresses tumorigenicity. Cancer Res 69: 1135-1142, 2009.

24. Yan D, Ng WL, Zhang X, Wang P, Zhang Z, Mo YY, Mao H, Hao C, Olson JJ, Curran WJ and Wang Y: Targeting DNA-PKes and ATM with miR-101 sensitizes tumors to radiation. PLoS One 5: e11397, 2010.

25. Buechner J, Tømte E, Haug BH, Henriksen JR, Løkke C, Flægstad T and Einvik C: Tumour-suppressor microRNAs let-7 and mir-101 target the proto-oncogene MYCN and inhibit cell proliferation in MYCN-amplified neuroblastoma. Br J Cancer 105: 296-303, 2011.

26. Tuttle RM, Haugen B and Perrier ND: Updated American Joint Committee on cancer/tumor-node-metastasis staging system for differentiated and anaplastic thyroid cancer (Eighth Edition): What changed and why? Thyroid 27: 751-756, 2017.

27. Chuang-Bo Y, Tai-Ping H, Hai-Feng D, Yong-Jun J, Xi-Rong Z, Guang-Ming M, Chenglong R, Jun W and Yong Y: Quantitative assessment of the degree of differentiation in colon cancer with dual-energy spectral CT. Abdom Radiol (NY) 42: 2591-2596, 2017.

28. Liu G, Friggeri A, Yang Y, Park YJ, Tsuruta Y and Abraham E: miR-147, a microRNA that is induced upon Toll-like receptor stimulation, regulates murine macrophage inflammatory responses. Proc Natl Acad Sci USA 106: 15819-15824, 2009. 
29. Livak KJ and Schmittgen TD: Analysis of relative gene expression data using real-time quantitative PCR and the 2(-Delta Delta C(T)) method. Methods 25: 402-408, 2001.

30. Gaidatzis D, van Nimwegen E, Hausser $\mathbf{J}$ and Zavolan $\mathrm{M}$ Inference of miRNA targets using evolutionary conservation and pathway analysis. BMC Bioinformatics 8: 69, 2007.

31. Van Peer G, Lefever S, Anckaert J, Beckers A, Rihani A, Van Goethem A, Volders PJ, Zeka F, Ongenaert M, Mestdagh P and Vandesompele J: miRBase tracker: Keeping track of microRNA annotation changes. Database (Oxford) 2014: pii: bau080, 2014.

32. Agarwal V, Bell GW, Nam JW and Bartel DP: Predicting effective microRNA target sites in mammalian mRNAs. eLife 4 e05005, 2015.

33. Chen CZ, Li L, Lodish HF and Bartel DP: MicroRNAs modulate hematopoietic lineage differentiation. Science 303: 83-86, 2004.

34. Cheng AM, Byrom MW, Shelton J and Ford LP: Antisense inhibition of human miRNAs and indications for an involvement of miRNA in cell growth and apoptosis. Nucleic Acids Res 33: 1290-1297, 2005.

35. Croce $\mathrm{CM}$ and Calin GA: miRNAs, cancer, and stem cell division. Cell 122: 6-7, 2005

36. Karp X and Ambros V: Developmental biology. Encountering microRNAs in cell fate signaling. Science 310: 1288-1289, 2005.

37. Mitomo S, Maesawa C, Ogasawara S, Iwaya T, Shibazaki M, Yashima-Abo A, Kotani K, Oikawa H, Sakurai E, Izutsu N, et al: Downregulation of miR-138 is associated with overexpression of human telomerase reverse transcriptase protein in human anaplastic thyroid carcinoma cell lines. Cancer Sci 99: 280-286, 2008.

38. Chen LG, Xia YJ and Cui Y: Upregulation of miR-101 enhances the cytotoxic effect of anticancer drugs through inhibition of colon cancer cell proliferation. Oncol Rep 38: 100-108, 2017.

39. Gramantieri L, Ferracin M, Fornari F, Veronese A, Sabbioni S, Liu CG, Calin GA, Giovannini C, Ferrazzi E, Grazi GL, et al: Cyclin G1 is a target of miR-122a, a microRNA frequently down-regulated in human hepatocellular carcinoma. Cancer Res 67: 6092-6099, 2007

40. Chan JA, Krichevsky AM and Kosik KS: MicroRNA-21 is an antiapoptotic factor in human glioblastoma cells. Cancer Res 65 : 6029-6033, 2005.

41. Yan LX, Huang XF, Shao Q, Huang MY, Deng L, Wu QL, Zeng YX and Shao JY: MicroRNA miR-21 overexpression in human breast cancer is associated with advanced clinical stage, lymph node metastasis and patient poor prognosis. RNA 14: 2348-2360, 2008.

42. Iorio MV, Ferracin M, Liu CG, Veronese A, Spizzo R, Sabbioni S, Magri E, Pedriali M, Fabbri M, Campiglio M, et al: MicroRNA gene expression deregulation in human breast cancer. Cancer Res 65: 7065-7070, 2005.

43. Nicoloso MS and Calin GA: MicroRNA involvement in brain tumors: From bench to bedside. Brain Pathol 18: 122-129, 2008.
44. Schepeler T, Reinert JT, Ostenfeld MS, Christensen LL, Silahtaroglu AN, Dyrskjøt L, Wiuf C, Sørensen FJ, Kruhøffer M, Laurberg S, et al: Diagnostic and prognostic microRNAs in stage II colon cancer. Cancer Res 68: 6416-6424, 2008.

45. Omerovic J, Laude AJ and Prior IA: Ras proteins: Paradigms for compartmentalised and isoform-specific signalling. Cell Mol Life Sci 64: 2575-2589, 2007.

46. Bonfrate L, Altomare DF, Di Lena M, Travaglio E, Rotelli MT, De Luca A and Portincasa P: MicroRNA in colorectal cancer: New perspectives for diagnosis, prognosis and treatment. J Gastrointestin Liver Dis 22: 311-320, 2013.

47. Frampton AE, Krell J, Gall TM, Castellano L, Stebbing J and Jiao LR: miR-15b and miR-17 are tumor-derived plasma microRNAs dysregulated in colorectal neoplasia. Ann Surg 262: e61-e62, 2015.

48. Diosdado B, van de Wiel MA, Terhaar Sive Droste JS, Mongera S, Postma C, Meijerink WJ, Carvalho B and Meijer GA: MiR-17-92 cluster is associated with 13q gain and c-myc expression during colorectal adenoma to adenocarcinoma progression. Br J Cancer 101: 707-714, 2009.

49. Chandramouli A, Onyeagucha BC, Mercado-Pimentel ME, Stankova L, Shahin NA, LaFleur BJ, Heimark RL, Bhattacharyya AK and Nelson MA: MicroRNA-101 (miR-101) post-transcriptionally regulates the expression of EP4 receptor in colon cancers. Cancer Biol Ther 13: 175-183, 2012.

50. Strillacci A, Valerii MC, Sansone P, Caggiano C, Sgromo A, Vittori L, Fiorentino M, Poggioli G, Rizzello F, Campieri M and Spisni E: Loss of miR-101 expression promotes Wnt $/ \beta$-catenin signalling pathway activation and malignancy in colon cancer cells. J Pathol 229: 379-389, 2013.

51. Tsujii M and DuBois RN: Alterations in cellular adhesion and apoptosis in epithelial cells overexpressing prostaglandin endoperoxide synthase 2. Cell 83: 493-501, 1995.

52. Kalluri R and Weinberg RA: The basics of epithelial-mesenchymal transition. J Clin Invest 119: 1420-1428, 2009.

53. Demir R, Naschberger L, Demir I, Melling N, Dimmler A, Papadopoulus T, Sturzl M, Klein P and Hohenberger W: Hypoxia generates a more invasive phenotype of tumour cells: An in vivo experimental setup based on the chorioallantoic membrane. Pathol Oncol Res 15: 417-422, 2009.

This work is licensed under a Creative Commons Attribution-NonCommercial-NoDerivatives 4.0 International (CC BY-NC-ND 4.0) License. 